\title{
Degree of Awareness and Reception of Local Language Use in Formal Education and New Technologies by the Youth in Africa: Insight from Cameroon
}

\author{
Gabriel D Djomeni \\ Faculty of Letters and Social Sciences, University of Dschang
}

\begin{abstract}
This study aims at shedding light on whether or how the youth receive the use of local languages in education and technologies in Cameroon. With data collected through questionnaire or based on quantitative data, the study sets out to provide an accurate answer to the following question: How are the youth aware of the teaching of languages in formal education and use in new technologies such as internet? A deep scrutiny of this main question reveals through analysis that recent introduction of Cameroon tongues into the formal school system has paved the way to a greater awareness by the youth of local languages and their use in education and new technologies. The study further unveils that the teaching of Cameroon tongues is a doorstep toward a better reception of local languages and their acknowledgement as the main tool for sustainable development by the youth, future leaders, who will therefore be prepared to foster change for the transformation of the continent.
\end{abstract}

Keywords: awareness, local language, education, technologies, youth

DOI: $10.7176 / J L L L / 69-03$

Publication date:June 30th 2020

\section{Introduction}

Almost over two decades ago now, a new wind in favour of African tongues is been blowing all over the African continent and even in the world. There has been growing concerns by African institutions and governments on the promotion, protection and use of African languages notably in formal education so that it could became a tool for the sustainable development of the continent. These concerns came up as the result of national and international pressures from NGOs. This move has been taken by Cameroon government, namely with the introduction of Cameroon languages into the formal school curricula at the primary, secondary and Higher education. In this vein, higher teacher training colleges of Yaoundé (University of Yaoundé I) and henceforth Bertoua (University of Ngaoundere) have opened a section for the training of teachers specialised in the teaching of Cameroonian languages and cultures. Almost a decade of this formal teaching - the experimentation been carried out long ago within PROPELCA (Operational programme for teaching languages in Cameroon) (See Tadadeu, M.et.al. 2004 for further discussion), a research ran by ISH (Institut des Sciences humaines), the University of Yaoundé and later NACALCO and SIL-Cameroon-, we thought it would be good to assess how the young generation of Cameroonians, particularly those who were not furthering their studies in classic universities where learners, whatever their field of specialisation, are exposed more or less to debates on languages. Therefore, we decided to survey business schools students who have a very limited exposure to language debate. This was to search for the reliability of the on-going practice and to better probe the situation. In order to better carry out the survey, we formulated a number of questions: What could be the youth degree of awareness of local language teaching in Cameroon and their use in new technologies in Cameroon? What do they think about those languages? In our search to provide these questions adequate answers, we set a questionnaire that was submitted to a number of English and French speaking respondents, business school learners. The collected data was analysed using both quantitative and qualitative methods. In order to delve into the topic, we have structured the research as follows: Initially, we exposed on genesis of the study. Thereafter, we examined the problem and the problematic underpinning it. The following section looked at the hypothesis, the research questions and the theoretical and methodological bases that back the analysis. The delimitation and limits of the study leads to the discussion of the key findings, namely the results obtained through interpretation.

\section{Genesis of the study}

The present analysis was triggered by a critical observation of the youth with regards first to mother tongue oral practice and the recent development undergone by the teaching of local languages in formal education in some African countries, notably in formal education. This quantitative study provides an idea about the concern.

The issue of education and development of African languages and their use in formal education is no more a very new discourse in both academia and social life in Africa and the whole world. It has almost become axiomatic that African languages are part of the mostly neglected natural resources of the continent. Furthermore, we all know that languages are the channel through which cultures widespread. Taking this into consideration, we have decided to find out how recently secondary school leavers, notably those in their first or second year in business 
schools in the higher education are aware of their mother tongue and how they perceive the development of those languages and their teaching in formal education along their use in new technological hubs. This has led to the setting of the problematic of the study.

\section{Problem and problematic}

It is henceforth a truism to state that most Africans are still stereotyped by colonisation from which they are still suffering negative impacts. The mind-set built since this era remains indelible in most African minds and is very difficult to clear it out of their psychology, social behaviours and attitudes. This situation can explain why most of the policies taken by most African governments until today are exocentric, i.e., they are not initially thought based on the real needs of the people at the grassroots. This is the result of education systems where, in most cases, the language (s) for knowledge transmission is/are colonial language(s) raised to the status of official languages and even national languages by many States. However, the move taken by countries such as South Africa, Tanzania (Brock-Utne \& Holmarsdottir, 2004), Rwanda (Samuelson \& Freedman, 2010) and some NGOs (ADEA, 2006), among others in their language policies is to be praised. Yet, a lot is still to be done in order to make the younger generation of Africans aware of the goods of their own tongues and their impact in the quality education and health care delivery they are supposed to receive. In other words, African languages shall be used as the backbone to the sustainable development of the continent. Most of the African youth are still very far from grasping this reality. This justifies why we have committed ourselves in finding whether and how far, they are aware or not of their mother tongues given the recent observation in intergenerational language transmission which is gradually slowing down, and how this youth receive the discourse on African language development, and use in formal education. The logical problematic from which arose the topic was formulated as follows: What can be the degree of awareness and reception of African languages' development and use in education among the youth in African and in Cameroon in particular?

This problematic led to the hypothesis and the research questions.

\section{Hypothesis and research questions}

The research was driven by the following hypothesis: There seems to be a mitigated degree of awareness and reception of mother tongue education and African language development among the youth in Africa especially those who are not studying arts and sciences and mainly those in higher education, studying business in business private Universities.

From the above stated hypothesis, the following research questions arose:

- $\quad$ Are African youth of today capable to identify their mother tongue?

- How do they perceive it and how do they perceive other African languages?

- $\quad$ Do they think African languages can be source of development?

- $\quad$ Are they aware that Cameroonian languages are formally thought at schools?

- $\quad$ Do the youth think African languages, namely their mother tongue could be used on new media and IT gadgets in general?

- What can be the degree of awareness of African language development by the youth in Africa, notably those in business schools?

- What could be the degree of reception of the practice by them with mother tongue education?

We attempted to provide an answer to each of these preoccupations along the analysis.

\section{Methodology}

This section discusses data collection techniques, theoretical background and population sampling.

\subsection{Data collection technique}

In order to collect the data useful for the present study, we initially elaborated a questionnaire made up of 23 questions. Therefore, our data was essentially collected through questionnaire because it was deemed the most relevant technique for this kind of study. The questionnaire was organised into two main sections.

\subsection{Sampling the population of the study}

The survey was carried out on a total population of 352 respondents of both English and French speaking education background, students in business schools in higher education in Cameroon. The randomly-sampled population was made up of 108 male students and 244 female students. Among them, there were 45 male and 142 female French speaking students in contrast to 63 male and 102 female English speaking students. In fact, we wanted an inclusive survey that takes into account both English and French speaking students. The French speaking students were those registered for the BTS (Brevet de Techniciens supérieurs) while the English Speaking were those registered for HND (Higher National Diploma).

By choosing two distinct groups with each speaking and official language of Cameroon, we wanted to also 
find out whether the first official language (OL1) culture has a certain degree of impact either positive or negative on respondents as far as their mother tongues were concerned.

On the other hand, formal classroom setting was chosen as the date collection setting. The interviewees were all between 15 and 25, just almost one-year or a few months secondary school leavers. The choice for the recent secondary school leavers was underpinned by the assumption that they were exposed to the discourse on the teaching of Cameroonian languages since its formal introduction in the first cycle of the secondary school's curricula and therefore will have the knowledge to address the questionnaire.

Higher education was chosen because it is representative of the linguistic diversity and regional origin of the students. In fact, you could easily find among the respondents Cameroonians from the ten regions of the country. The following (table 1) summarises the figures provided above per language group.

Table 1: Total of questionnaire respondents

\begin{tabular}{|l|l|l|l|}
\cline { 2 - 3 } \multicolumn{1}{c|}{} & \multicolumn{2}{l|}{ Respondents } & Total per language \\
\hline Gender & male & female & \\
\hline French speaking & 45 & 142 & 187 \\
\hline English speaking & 63 & 102 & 165 \\
\hline Totals & 108 & 244 & \multicolumn{1}{|c}{} \\
\cline { 1 - 2 } General totals & 352 & \multicolumn{2}{|l}{}
\end{tabular}

The English speaking and the French speaking participants were compared between them. Male and female respondents were first compared among them within the same group before been compared between in the two groups.

As (table1) above exhibits, randomly, the number of female respondents was more than double that of male ones.

\section{Delimitation and limitation of the project}

Because the topic focuses on the degree of awareness and reception of African languages and mother tongue education by the Youth in Africa, in order to access the relevant data, we limited the study to the case of Cameroon. Then we surveyed the youth and particularly the youth of business schools, two in Douala the economic capital and two in Yaounde the political capital city of the country. We further surveyed only business school of higher education. We did not bother to extend the survey to other Higher education's areas of learning because they were considered to be mostly exposed to language related discourses than their business schools counterparts. Furthermore, we did not considered the youth in the streets and villages and even those in primary and secondary schools as capable of impacting our study although the study itself could be replicated on them either in the same or different perspective.

\section{Results and interpretation}

We are going to break down the presentation of the results into subsections. In fact, the results will be presented as per each section of the questionnaire.

\subsection{Self-assessment of mother tongue knowledge}

The first section of the questionnaire was dedicated to finding out whether the respondents were able to name their mother tongue or what looks like that. The prime observation was that some of those who were able to clearly identify their mother tongue, giving its real name were coming from families where both parents head the same Cameroon local languages.

The greatest majority of the respondents were aware of their mother tongue and could give its real name. Those who were unable to do so were confused between the ethnonym and the glossonym i.e., the name of the geographical area or locality where the language is spoken and the language name itself. In fact, the following (table 2) contains the results obtained as per language group and gender.

Table 2: Knowledge of Mother tongue name

\begin{tabular}{|l|l|l|l|l|}
\hline Gender & \multicolumn{2}{|c|}{ Male } & \multicolumn{2}{c|}{ Female } \\
\hline Awareness & do know & do not know & Do know & Do not know \\
\hline English speaking & 32 on $45=71.11 \%$ & 13 on $45=28.89 \%$ & 90 on $102=88.24 \%$ & 12 on $102=11.76 \%$ \\
\hline French speaking & 45 on $63=71.42 \%$ & 18 on $63=28.58 \%$ & 127 on $142=89.44 \%$ & 15 on $142=10.56 \%$ \\
\hline
\end{tabular}

This result is summarised by the following diagram (D1). 


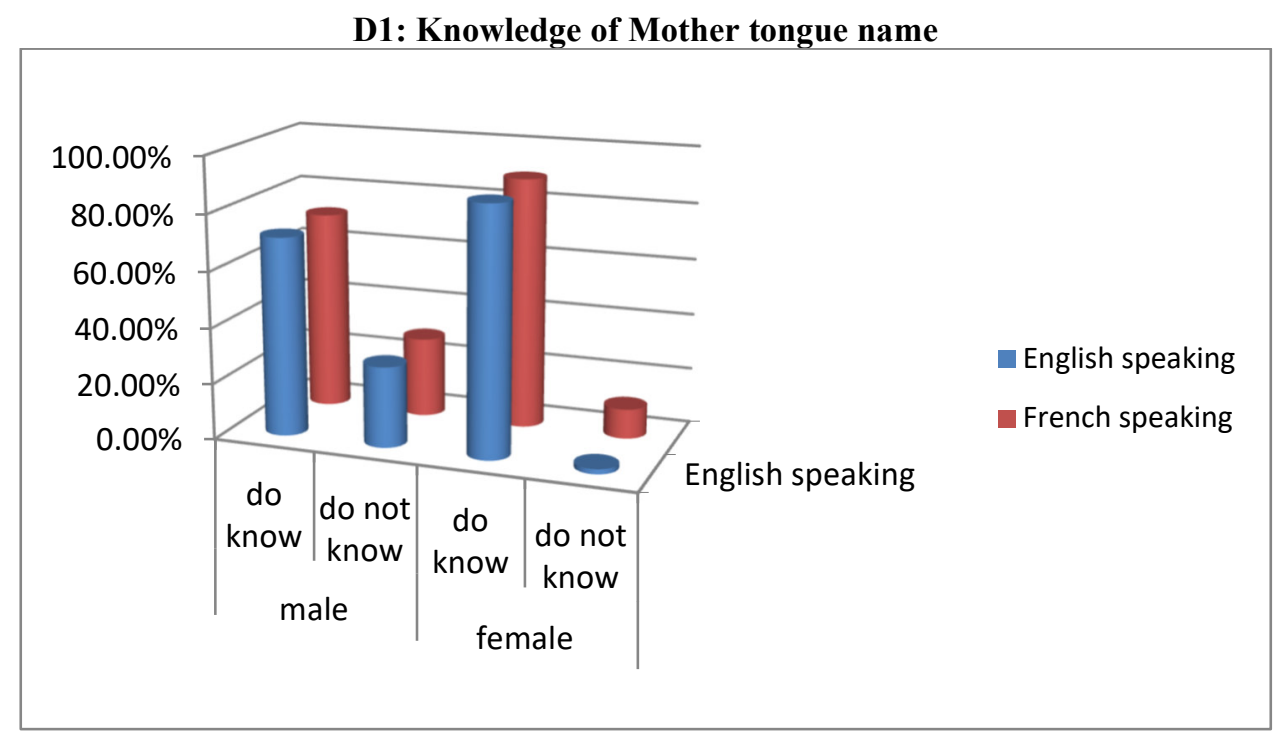

The diagram just above allows capturing both the number of each category of the respondents as described above who knew their mother tongue and those who did not and their percentage. It is obvious from the graph that both English and French speaking respondents in their largest majority knew how their mother tongue was called. On the other hand, very few respondents said they could speak another Cameroonian language out of their mother tongue. The answer to this section took us to the following one which focused on the writing system.

\subsection{Awareness of the writing system of Cameroonian mother tongues}

Tadadjeu \& Sadembouo (1984) set some general frames for writing and reading Cameroonian languages. Therefore, this aspect of the questionnaire intended to find out whether the respondents were aware of these principles. The questions were based solely on Cameroonian languages because randomly, it happened that no foreigner was involved in the process.

The respondents were questioned here about whether they were aware of the writing systems of Cameroonian languages or not and specifically that of their mother tongue.

First and foremost, the question related to the knowledge of the existence of a writing system of Cameroonian languages in general was answered positively by the greatest majority of the respondents. In fact, as for the question related to the knowledge of one's mother tongue writing system, both English and French speaking respondents expressed their knowledge of the alphabet and orthography of their mother tongue. The knowing of how to write and read local languages is still very problematic because as the results show, for the English speaking respondents, 132 on 165 , i.e., $80 \%$ both male and female argued that they do not know to do so. It goes alike with the French speaking with 146 on 187, i.e., $78.07 \%$ both male and female respondents strongly said that they do not know the writing system of their mother tongue.

The following diagram (D2) captures the percentages discussed above.

D2: Awareness of the writing system of one's Cameroonian mother ton

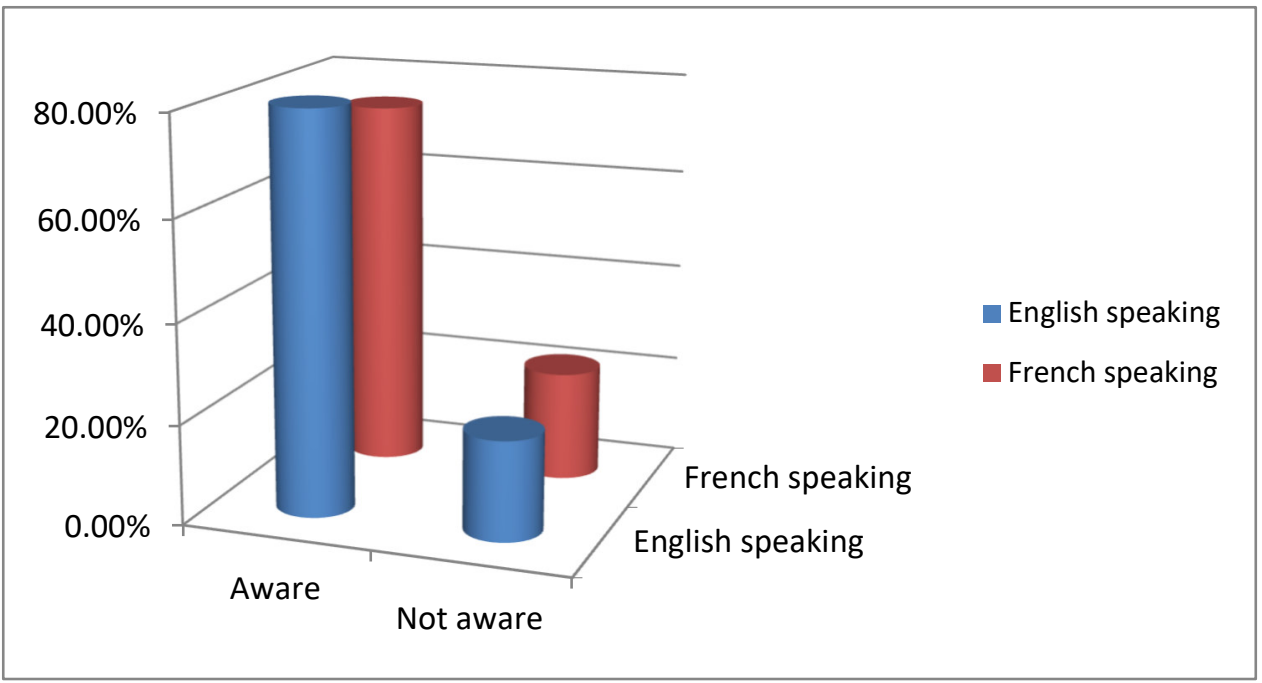


The diagram clearly demonstrates that both English and French speaking in their largest majority are ignorant of the writing system of their mother tongue. In fact, they are neither able to write nor to read their Cameroonian language.

\subsection{Awareness and willingness of mother tongue in formal education in Cameroon}

Questions 10 to 6 of the questionnaire were set to probe the awareness or not of the teaching of Cameroonian languages from participants who almost freshly left secondary schools. The respondents were requested to express their opinion about whether they think if African languages in general can be taught at school. To this, the largest majority of the whole surveyed individuals answered in a positive direction. In fact, 291 on 352 , i.e., $82.67 \%$ know that Cameroonian languages were formally taught in Secondary school. For the French speaking respondents 159 on 187, i.e., 123 on 142 females, 86.62\% and 36 on 45 males, i.e., 80\% as compared to 132 on 165 for the English speaking counterparts, i.e., 81 on $102,79.42 \%$ females and 51 on 65 boys, i.e., $78.46 \%$ said that they will be very happy if the teaching of local tongues becomes compulsory in all levels of formal education in Cameroon. Though the respondents did not know about existing documents clearly providing instructions on the teaching of African or Cameroonian languages like Tadadjeu, Sadembouo \& Mba (2004), they were happy to see their mother tongue at school. This result is summarised in the diagram below (D3).

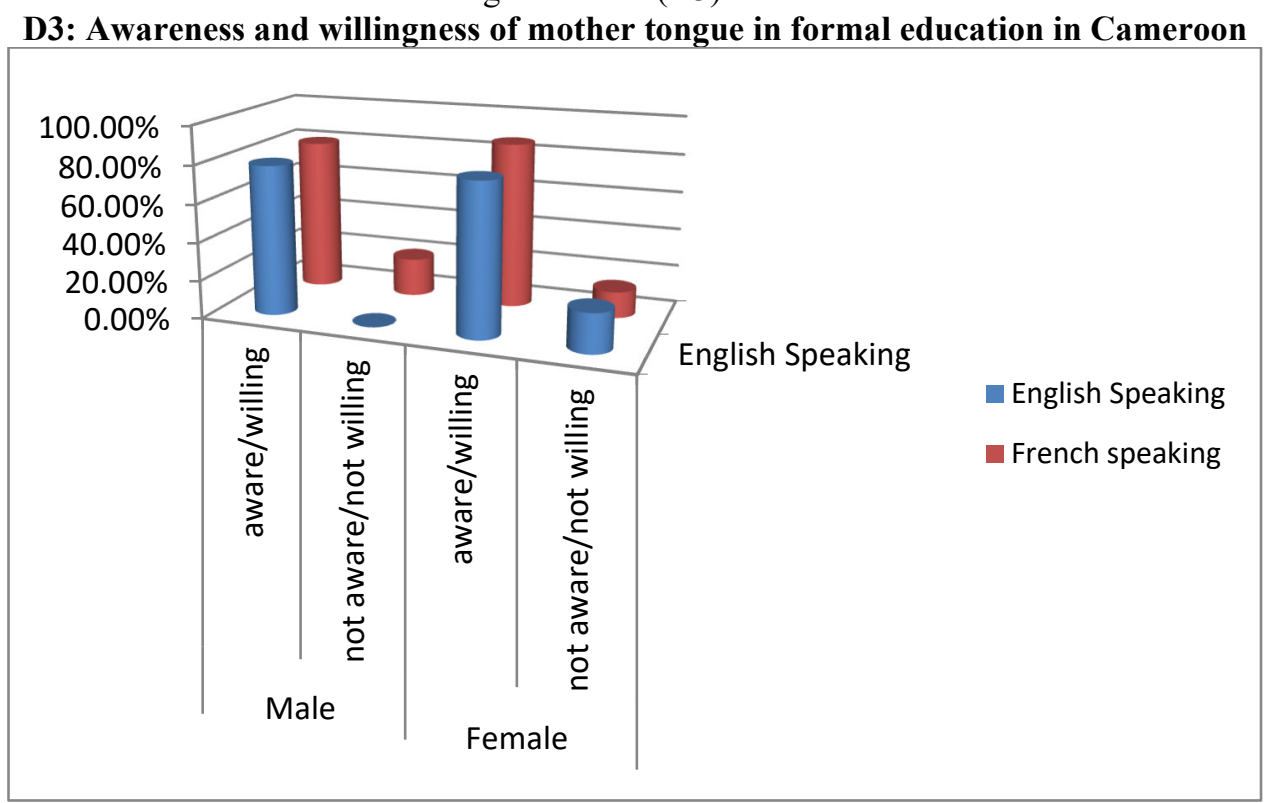

In question 10, an open question, a number of reasons were put forward to justify the teaching or not of African tongues at school (see table 3 below). These reasons are summarised in the table below in two axes, one for and other against. Yet, it should be pointed out that the greatest majority were for the MT to be effective and generalised.

Table 3: Reasons why African languages should be taught nor not at school

\begin{tabular}{|c|c|}
\hline Arguments for & Arguments against \\
\hline $\begin{array}{l}\text { prepare the true emergence of the continent and that of the } \\
\text { country in particular }\end{array}$ & $\begin{array}{l}\text { there are too many languages in Africa and } \\
\text { in Cameroon in particular }\end{array}$ \\
\hline protect national and individual identity & $\begin{array}{l}\text { mother tongues should be spoken at home } \\
\text { and not at school }\end{array}$ \\
\hline promote African languages & African languages are symbols of division \\
\hline avoid local languages to fade out & there are already languages and French \\
\hline $\begin{array}{l}\text { it is important to know as many languages as possible including } \\
\text { local languages }\end{array}$ & \\
\hline $\begin{array}{l}\text { knowledge and teaching of local languages is a real sign of } \\
\text { freedom }\end{array}$ & \\
\hline $\begin{array}{l}\text { african languages are key tools for the development of the } \\
\text { country }\end{array}$ & \\
\hline $\begin{array}{l}\text { they should be taught at school because English and French, the } \\
\text { official languages, are foreign languages }\end{array}$ & \\
\hline
\end{tabular}


female English speaking, i.e., $83.33 \%$ and 57 on 63 men, i.e., $90.48 \%$, found in the local languages the same values like in English and French. We notice however that that rate is lower for French speaking respondents than for their English counterparts. Those who did not find in local languages the same value like in English and French argued that this is because the latter mentioned are official languages and are spoken everywhere according to them.

As for mother tongue education and development, in question 15, both English and French speaking overwhelmingly stated that in case knowledge of a Cameroonian mother tongue is required for jobs, they will be obliged to learn it by rushing to schools or centres where they are taught, investing time and money to get the required degree of knowledge required for the job. This clearly shows that when some functions are attached to language learning, notably some prestigious functions such as access to job and employment, being them minority languages or not, they can attract interests and yield to a real source of motivation. This can explain why only 08 on 352 , i.e., $2.28 \%$ of the respondents said that they will be very sad if that happens but fail to indicate the action they will undertake. The diagrammatic representation (D4) below helps to capture the figures mentioned above.

\section{D4: Mother tongue education and development}

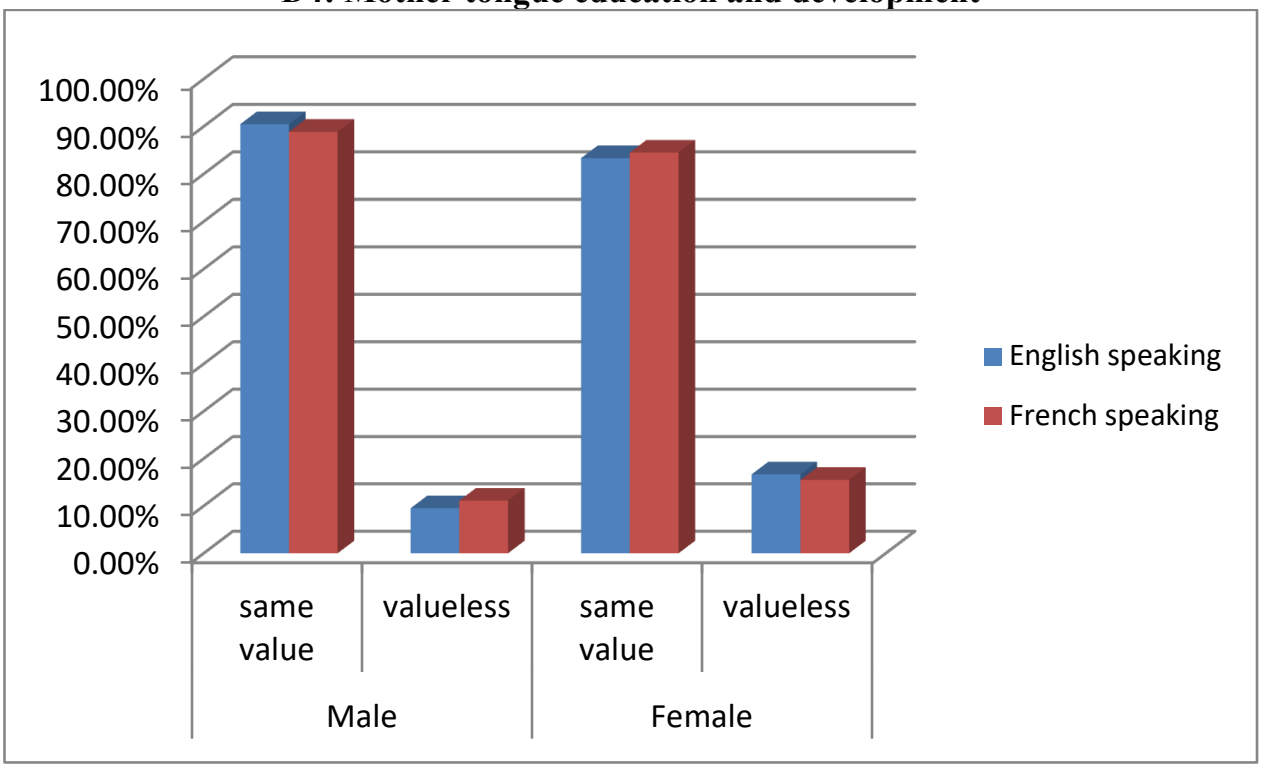

\subsection{African languages and new technologies}

Djomeni \& Sadembouo (2017) in their discussion on the use of African languages on the internet and notably in social media pointed out that the younger generation or rather the youth are more exposed to recent technology gadgets. Therefore, it will be easier to find out whether they are aware that African languages can also be used or are used on the different platforms offered by new technologies. Based on this assumption, we focus on the issue in this section.

The questions were all related to African /Cameroonian tongues and new technologies. When it was asked whether African languages could be typed on computers and printed, the overwhelming majority answered positively. In effect, 113 on 142 females, i.e., 79.57\% and 41 on 45, i.e., 91.11\% male French speaking students and 96 on 102, i.e., $94.12 \%$ female as compared to 54 on 62, i.e., $87.10 \%$ male students for English speaking participants, believed so as summarised in the following table (D5). 


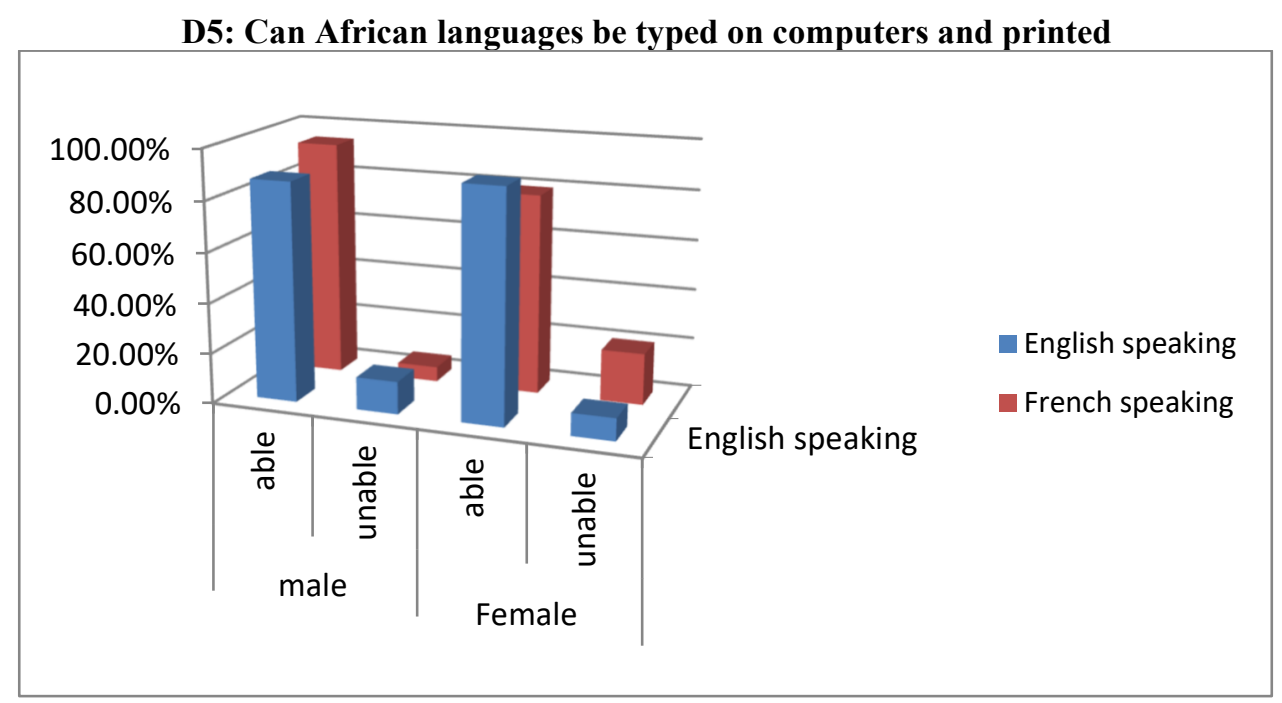

When they were asked to know whether Cameroonian languages could be used on tablets and smart phones (android and iPhones, windows smartphones), a total of 111 positive answers on 165 participants was provided while for English speaking, 182 answered positively on 187 respondents as indicated in the following table.

Table 4: Usability of Cameroonian languages on smartphones and tablets

\begin{tabular}{|l|l|l|}
\hline language & Number of participants who believe & Number of participants who do not believe \\
\hline English speaking & 111 & 54 \\
\hline French speaking & 182 & 5 \\
\hline
\end{tabular}

A total of 161 on 165 for the English speaking thought that Cameroonian languages could be used on social media; this was sustained by the answer of their French counterparts whom only 13 on 187 were sceptical about that. The curiosity here is that the majority of those who believed that Cameroonian languages could not be used on social media were of French speaking background. Is this probably because they are not as aware of the technological evolutions or because they do not think local languages have the same possibilities like any other language to be present or be used on these networks or is it also because their exposure to social media and IT development is limited as compared to their counterparts. Because there is no room now to provide an adequate answer to this question, it might be addressed in a further study.

\subsection{African languages and their popularisation}

This section was intended to find out how African languages could be popularised among the youth. Therefore, questions 22 to 24 were set to this end. A number of possibilities were proposed by the respondents. What they proposed for this to happen could be summarised as follows:

- $\quad$ teach them at school;

- $\quad$ find strategies to globalise them;

- $\quad$ they must be imposed in education at all levels.

Furthermore, they put that administrative authorities were supposed to be sensitised together with the whole Cameroonian/African population and begin to teach local tongues as from kindergarten. They also proposed that local African tongues should become part of the subjects of official examination and with a high credit. If taken into account, this resolution will oblige all learners to pay more attention and give more prestige to local mother tongues. In this vein, the recent move and decisions taken by the Cameroon Minister of Secondary education by making Cameroonian languages and cultures part of the questions papers for the BEPC (French speaking examination to the end of the first cycle of secondary education) examination is to be praised, though the subject features among the non-compulsory ones at that examination.

The respondents presented a battery of arguments about what they propose for the promotion and development of African/Cameroonian languages as follows:

- $\quad$ choose one language for all;

- $\quad$ imposing through official laws and texts the teaching/learning of local languages from basic education;

- $\quad$ popularise writing and reading in local languages;

- $\quad$ make local languages more visible on the internet;

- $\quad$ publish more in local languages;

- $\quad$ organise competitive games to promote knowledge in local languages;

- $\quad$ stakeholders should organise forums for mother tongue on social media networks.

The last question of the questionnaire aimed at knowing if the participants would volunteer in development 
process of their mother tongue if it does not have a writing system. The result was quite mitigated as whether one was addressing English or French speaking respondents. In fact, 126 on 165, 76. 36\% for the English speaking were ready for the task for only $33.68 \%$ i.e., 63 on 187 for the French speaking. As for the reason why they will either volunteer or not, the following reasons were provided:

Table 5: Why or why not volunteering for MT development

\begin{tabular}{|c|c|}
\hline Would & Would not \\
\hline give more pride and value to my language & It can't help \\
\hline for my language to be known to the world too & It is valueless and worthless \\
\hline to allow all my people access knowledge in the language & I do not care \\
\hline allow traditional knowledge to be sold & \multicolumn{1}{|c}{} \\
\cline { 1 - 2 } &
\end{tabular}

In general, it is observed that the introduction of Cameroon local languages into the curricula of secondary education has since then raised a certain degree of awareness among the youth. In fact, this can be seen from the responses provided by the respondents with regards to knowledge of their mother tongues. Knowledge of mother tongue is proven to be determinant in the shaping of the minds of the youth because they are the future generation who will transform or rethink education systems in Africa tomorrow and for tomorrow. When they are overwhelmingly aware that their mother tongue can boost development and especially the development of the continent, it can be foreseen that they will bring a new impetus to the transformation of the continent through education.

This can obviously be efficient only when the current leading generation trains the youths in the perspective of inculcating in them the well-foundation for promoting, developing and using African tongues in education so as to be able to reach a critical amount of quality workforce for the development of the continent.

\section{Conclusion}

The analysis above sets out to probe whether the youth were aware of the recent developments in the teaching of Cameroonian languages and their use on the Internet. The analysis demonstrates through English and French speaking young Cameroonians that learners in Business higher institutes of privates Universities that the introduction of Cameroon local languages and cultures in the curricula in formal education has paved a long way acknowledging and popularising Cameroon tongues, raising awareness among the majority interviewed, nurturing more self-esteem and pride of their language though some are from knowing that Cameroon local languages have the same possibilities like others be present online and used on new technologies. The analysis further shows that this acknowledgement means the youth is being prepared through the teaching of their mother tongues at schools as future ambassadors of multilingualism and multiculturalism in Cameroon. They are slowly been empower with strong tools that will help them tackle one of the major challenges they, failure of intergenerational transmission. Only the fact they are aware of this and are pointing an accusation finger to their parents shows they will be committed tomorrow to make use of their mother tongues or supposed mother tongues and ensure their transmission to their offspring. Developing the pride to learn from their immediate environment constitutes a step forward in Africa to reverse the dire scandalous situation in education -from the unknown to the known- and language-in-education policies.

\section{References}

ADEA (Association for the Development of Education in Africa) Report. (2006). Proceedings of the Regional Conference and Expert Meeting on Bilingual Education and the Use of Local Languages. Available at http://www.adeanet.org/biennial 2006/doc/document/B3_1+Rapport\%20Windhoek_en.pdf

Bitjaa Kody, Z. D. (2001). “Attitudes et représentations linguistique à Yaoundé”. In M. Tadadjeu, M \& P. Nguessimo Mutaka, (Eds.), Topics in African linguistics and Universology. African Journal of Applied Linguistics (AJAL) no2, Centre ANACLAC de Linguistique appliquée, Yaoundé.

Brock-Utne, B. \& Holmarsdottir, H. (2004). "Language policies and practices in Tanzania and South Africa: Problems and challenges". International Journal of Educational Development. 24. 67-83. 10.1016/j.ijedudev.2003.10.002.

Djomeni, G.D \& Sadembouo. E. (2016). "African languages and digital media: practice, challenges and perspectives in Cameroon”. In Digital media and language revitalisation. Linguapax review no 4.3, 39-54, Linguapax International, Catalunya.

Samuelson, Beth \& Freedman, Sarah. (2010). "Language policy, multilingual education, and power in Rwanda". Language Policy. 9. 191-215. 10.1007/s10993-010-9170-7.

Tadadjeu M., Sadembouo E., \& Mba, G,. (2004). Pédagogie des langues maternelles africaines. Collection PROPELCA, $N^{\circ}$ 144-01, Série Publications scientifiques 001. Yaoundé: Éditions du CLA.

Tadadjeu, M \& Sadembouo, E. (1984). General alphabet of Cameroonian languages. Coll. PROPELCA no2, Yaoundé. 


\section{Appendix \\ Sociolinguistic questionnaire/ Questionnaire sociolinguistique}

This questionnaire is for research purposes. Please provide as much as possible an accurate answer to each question /Ce questionnaire est établi pour des fins de recherche. Nous vous prions d'être précis et concis dans vos réponses

\section{Personal information /Informations personnelles}

Sexe: Male/Masculin

Female /féminin

Age: $15-20$

$21-25$

$26-30$

31-Plus

$1^{\text {st }}$ official language/1e langue officielle:

Year of leaving high school/ Année de départ du secondaire:

1. What is mother tongue/Quelle est votre langue maternelle?

2. Where is it spoken/Où la parle-t-on?

3. Do you speak any other Cameroonian language? Yes No If yes, which one(s)?

4. What is the language of your father/Quelle est la langue de votre père?-

5.What is the language of your mother ?/ Quelle est la langue de votre mère?

6. Are you aware of the writing system of Cameroonian languages/Savez-vous que les langues camerounaises ont un système d'écriture? Yes/Oui

No/Non

7. Does your mother tongue has a writing system/ Votre LM a-t-elle un système d'écriture?

Yes/Oui

No/Non

8. Do you know to write and read your mother tongue? / Savez-vous lire et écrire votre langue maternelle? Yes/Oui

\section{No/Non}

a) If yes, where did you learn that? /Si oui, où l'avez-vous appris?

b) If no would you like to learn to write and read /Si non, voudriez-vous bien apprendre à la lire et à l'écrire?---Why/Pourquoi ?

9. Have you ever received a holiday class in your mother tonge ?/ Avez-vous déjà pris part au cours de vacances dans votre Langue maternelle? Yes/Oui No/Non

10. Do you think African languages can be taught at school ?/Pensez-vous qu'on peut enseigner les langues Africaines dans le système éducatif formel? Yes/Oui No/Non Why/Pourquoi?

11. Are you aware that Cameroonian languages are formally taught at school ?/Savez-vous que les langues camerounaises sont formellement enseignées à l'école?

Yes/Oui No/Non

12. What will be your feeling if you are told that mother tongue teaching will become a complusory component of your programme/education/ Quelle sera votre reaction si l'on vous informait que l'enseignement des langues camerounaises est obligatoire à tous les niveaux de votre cursus? 
13. Do you think your mother tongue can have the same value as English and French/Pensez-vous que votre langue maternelle peut avoir les memes valeurs que l'anglais et le français?

Why/Pourquoi?-

14. Do you believe that your mother tongue can help to boost the development of you locality and your country/ Pensez-vous que votre langue maternelle peut aider à stimuler le développement local et national?------Why?----

15. What would you do if good knowledge of a Cameroonian language is required for job application/Que feriezvous si l'on vous demandait des compétences dans une langues camerounaises pour obtenir un emploi?

African Languages and new technologies

16. Do you think Cameroonian languages could be typed and printed on computers and printers/Pensez-vous que les langues africaines peuvent être saisies et imprimées?

17. Do you think that it is possible to use Cameroonian languages on tablets, iphones and android phones/ Pensezvous qu'il soit possible d'utiliser les langues camerounaises sur les tablettes, les iphones et les androids?

18. Do you think it is possible to use Cameroonian languages to chat on social media (whasapp, youtube, twitter, facebook....)/ Pensez-vous qu'on peut utiliser les langues camerounaises pour communiquer sur les medias sociaux?

19. Have you ever experienced it/ L'avez-vous déjà essayé?-

20. If yes, how did you find it/ Si oui, comme l'avez-vous jugé?

21. What can be done to popularize the use of Cameroonian languages in education and formal domains/Selon vous, que peut-on faire pour vulgariser l'utilisation des langues camerounaises dans l'éducation formelle?

22. If you were to propose something for the promotion and development of African languages, what would you say/Que proposerez-vous pour une promotion efficace des langues africaines?

23. In case your language is not written, will be willing to work for its writing system/Si votre langue n'est pas écrite, series-vous volontaire pour travailler dans le sens de son développement sur le plan écrit?

Why/Pourquoi? 